18

\title{
Моделирование рулонных упаковок нанолент графона
}

\author{
() А.В. Савин, М.А. Мазо \\ Институт химической фризики им. Н.Н. Семенова РАН, \\ Москва, Россия \\ E-mail: asavin@center.chph.ras.ru
}

(Поступила в Редакцию 17 октября 2016 г.)

Предложена молекулярно-механическая модель нанолент графона (графена с односторонней гидрогенизацией), учитывающая деформации валентных связей, валентных и торсионных углов, невалентные ван-дер-ваальсовы и кулоновские взаимодействия атомов наноленты. С использованием модели найдены основные состояния нанолент. Показано, что прямоугольный фрагмент графона на подложке, образованной бесконечным плоским листом графена, формирует плоский монослой, а не взаимодействующий с подложкой фрагмент принимает выпуклую форму, внешняя сторона которой содержит присоединенные атомы водорода. Моделирование динамики показывает устойчивость односторонней структуры листа графона к тепловым колебаниям (при $T<900 \mathrm{~K}$ атомы водорода не переходят с одной стороны листа на другую). Неодинаковость сторон приводит к быстрому сворачиванию длинных свободных нанолент графона в рулонные структуры. Тепловые колебания не препятствуют образованию рулонов, а сами рулоны устойчивы к ним.

Исследование выполнено при финансовой поддержке Российского научного фонда (проект № 16-13-10302).

Вычислительные ресурсы предоставлены Межведомственным суперкомпьютерным центром РАН.

DOI: 10.21883/FTT.2017.06.44498.385

\section{1. Введение}

В последнее время большой интерес вызывают различные производные графена (гексагонального монослоя атомов углерода) [1-4], такие как графан (полностью насыщенный с обеих сторон водородом монослой графена) [5,6] и графон (монослой графена, насыщенный водородом только с одной стороны) [7-9]. Главной особенностью листа графона является неэквивалентность его сторон. Наличие присоединенных атомов водорода только на одной его стороне приводит к выпуклости свободного листа и сворачиванию в рулоны длинных нанолент.

Гидрогенизация графена может менять его электрические, магнитные и механические свойства $[10,11]$. Локальная односторонняя гидрогенизация может быть использована для изменения его геометрической структуры (создания изломов и выпуклостей) [12].

Возможность использования графона в значительной мере зависит от степени устойчивости его односторонней структуры к тепловым колебаниям. В первой работе, посвященной теоретическому анализу свойств графона [7], была предсказана его устойчивость при температуре $T=300 \mathrm{~K}$. Проведенное в [13] моделирование динамики графона показало возможность перескоков атомов водорода от одного атома углерода к другому. Моделирование динамики проводилось для малых фрагментов графона (в работе [13] была промоделирована динамика кластера $\left.\mathrm{C}_{54} \mathrm{H}_{60}\right)$.

Для анализа долговременной динамики крупных фрагментов графона воспользуемся молекулярно-механической моделью, учитывающей деформации валентных связей, валентных и торсионных углов, а также невалентных ван-дер-ваальсовых и кулоновских взаимодей- ствий атомов листа. С помощью метода молекулярной динамики далее показана устойчивость односторонней структуры графона к тепловым колебаниям при температуре $T<900 \mathrm{~K}$. Термически активированный переход атома водорода с одной стороны листа на другую возможен, только если не учитывать ван-дер-ваальсовы взаимодействия атомов водорода с атомами углерода. Далее показано, что наноленты графона на подложке имеют плоскую структуру, а отделенные от подложки наноленты быстро сворачиваются в рулонные структуры. Тепловые колебания не препятствуют образованию рулонов, а сами рулоны устойчивы к ним.

Рассмотренный нами механиз самосборки нанолент графона в рулоны позволяет объяснить образование рулонных структур при использовании гидротермального метода получения углеродных нанотрубок [14,15], при котором разогретый до температуры 800-900 ${ }^{\circ} \mathrm{C}$ поликристаллический графит опускают в сосуд с дистиллированной водой комнатной температуры. Здесь должно происходить одностороннее гидрирование внешних плоских слоев графита и образование из них рулонов при их отделении от кристалла.

\section{2. Модель наноленты графона}

Динамика листа идеального графена хорошо описывается при помощи потенциалов взаимодействия [16]: деформация валентной связи $\mathrm{C}-\mathrm{C}$ - потенциалом

$$
V(\rho)=\epsilon_{1}\left[e^{-\alpha\left(\rho-\rho_{0}\right)}-1\right]^{2}
$$

(где $\rho$ - текущая длина связи, $\rho_{0}=1.418 \AA-$ равновесное значение длины связи, $\epsilon_{1}=4.9632 \mathrm{eV}$ - энергия 
связи, параметр $\alpha=1.7889 \AA^{-1}$ задает жесткость связи $\left.K=2 \epsilon_{1} \alpha^{2}=508.9 \mathrm{~N} / \mathrm{m}\right)$,

деформация валентного угла $\mathrm{C}-\mathrm{C}-\mathrm{C}$ - потенциалом

$$
U\left(\mathbf{u}_{1}, \mathbf{u}_{2}, \mathbf{u}_{3}\right)=U(\varphi)=\epsilon_{2}\left(\cos \varphi-\cos \varphi_{0}\right)^{2}
$$

(где косинус валентного угла $\cos \varphi=-\left(\mathbf{v}_{1}, \mathbf{v}_{2}\right) /\left|\mathbf{v}_{1}\right|\left|\mathbf{v}_{2}\right|$, векторы $\mathbf{v}_{1}=\mathbf{u}_{2}-\mathbf{u}_{1}, \mathbf{v}_{2}=\mathbf{u}_{3}-\mathbf{u}_{2}$, векторы $\mathbf{u}_{1}, \mathbf{u}_{2}, \mathbf{u}_{3}$ задают координаты атомов углерода, образующих валентный угол, равновесное значение угла $\varphi_{0}=2 \pi / 3$, энергия $\left.\epsilon_{2}=1.3143 \mathrm{eV}\right)$. Деформации двугранных и торсионных углов описываются потенциалом

$$
W\left(\mathbf{u}_{1}, \mathbf{u}_{2}, \mathbf{u}_{3}, \mathbf{u}_{4}\right)=\epsilon_{3}(1+\cos \phi),
$$

где $\quad \cos \phi=\left(\mathbf{v}_{1}, \mathbf{v}_{2}\right) /\left|\mathbf{v}_{1}\right|\left|\mathbf{v}_{2}\right|, \quad$ векторы $\quad \mathbf{v}_{1}=$ $=\left(\mathbf{u}_{2}-\mathbf{u}_{1}\right) \times\left(\mathbf{u}_{3}-\mathbf{u}_{2}\right), \mathbf{v}_{2}=\left(\mathbf{u}_{3}-\mathbf{u}_{2}\right) \times\left(\mathbf{u}_{4}-\mathbf{u}_{3}\right)$, энергия $\epsilon_{3}=0.499 \mathrm{eV}$. Векторы $\mathbf{u}_{1}, \ldots \mathbf{u}_{4}$ задают положения атомов, образующих торсионный или двугранный угол.

Присоединение атома водорода к атому углерода меняет тип всех валентных связей этого атома. Поэтому здесь необходимо модифицировать потенциалы взаимодействия.

Валентную связь $\mathrm{C}-\mathrm{CH}$ тоже опишем потенциалом (1) с параметрами $\epsilon_{1}=4.01 \mathrm{eV}, \rho_{0}=1.51 \AA$, $\alpha=1.8 \AA^{-1}$ (жесткость связи $K=416.3 \mathrm{~N} / \mathrm{m}$ ) [17]. Валентная связь $\mathrm{C}-\mathrm{H}$ хорошо описывается потенциалом (1) с параметрами $\epsilon_{1}=4.28 \mathrm{eV}, \rho_{0}=1.11 \AA$, $\alpha=1.8 \AA^{-1}$ (жесткость связи $K=444.3 \mathrm{~N} / \mathrm{m}$ ) [18].

Валентный угол $\mathrm{C}-\mathrm{CH}-\mathrm{C}$ опишем потенциалом (2) с равновесным значением угла $\varphi_{0}=111.0^{\circ}$ и энергией $\epsilon_{2}=1.3 \mathrm{eV}$, а валентный угол $\mathrm{C}-\mathrm{C}-\mathrm{H}-$ потенциалом (2) с равновесным значением угла $\varphi_{0}=109.5^{\circ}$ энергией $\epsilon_{2}=1.0 \mathrm{eV}$.

Деформации торсионных и двугранных углов, в образовании грани которых не участвуют атомы углерода с присоединенными атомами водорода, опишем потенциалом (3). Если к одному из атомов углерода, образующих грань (ребро) торсионного (двугранного) угла, присоединен атом водорода, будем использовать потенциал

$$
W\left(\mathbf{u}_{1}, \mathbf{u}_{2}, \mathbf{u}_{3}, \mathbf{u}_{4}\right)=\epsilon_{4}(1+\cos 3 \phi)
$$

с энергией $\epsilon_{4}=0.03 \mathrm{eV}[17]$.

Отметим, что присоединение двух атомов водорода с одной стороны листа к атомам углерода, связанным валентной связью, энергетически невыгодно [19]. Поэтому будем рассматривать такие гидрированные с одной стороны наноленты, в которых к одному атому углерода присоединен атом водорода, а к трем соседним атомам углерода он не присоединяется (рис. 1,2). В таких структурах отсутствуют валентные связи $\mathrm{CH}-\mathrm{CH}$, валентные и торсионные углы, образованные этими связями. Поэтому соответствующие им потенциалы можно не задавать.

Присоединение атома водорода приводит к поляризации связи $\mathrm{C}-\mathrm{H}$. Квантовые расчеты показывают, что на атоме водорода находится заряд $q_{\mathrm{H}}=0.22 e$, а на

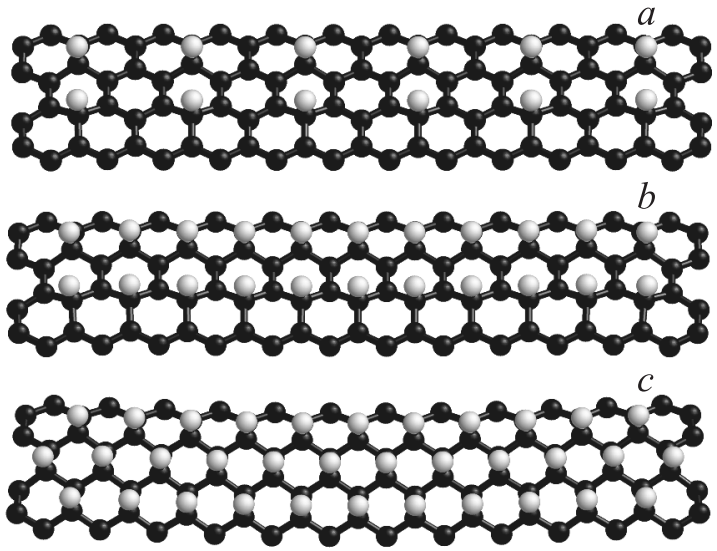

Рис. 1. Структуры нанолент графона с разной плотностью присоединенных атомов водорода на подложке плоского листа графена. $a-$ лента $\mathrm{C}_{100} \mathrm{H}_{12}, b-$ лента $\mathrm{C}_{100} \mathrm{H}_{22}, c-$ лента $\mathrm{C}_{100} \mathrm{H}_{34}$. Атомы водорода показаны светлыми шарами.

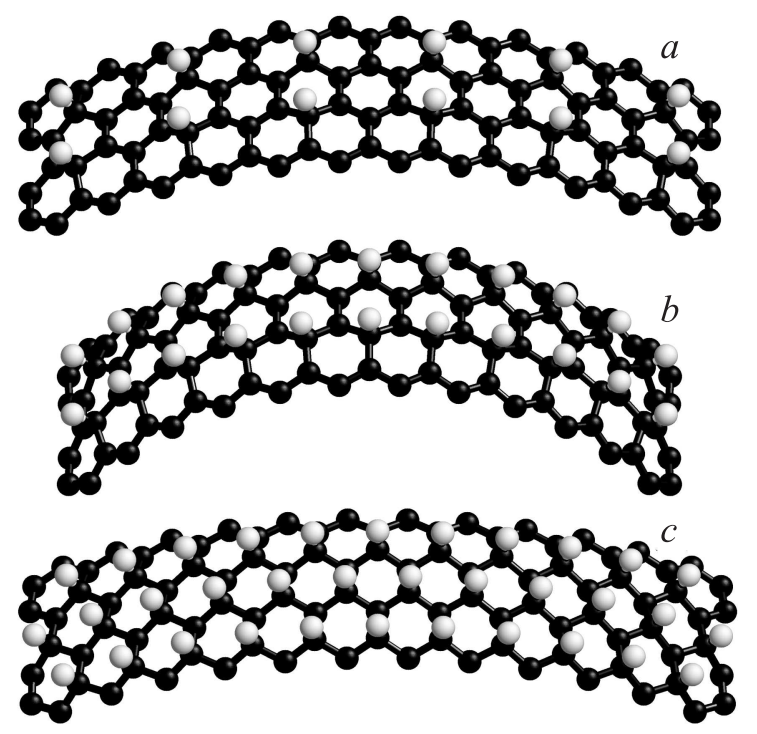

Рис. 2. Структуры свободных (не взаимодействующих с подложкой) нанолент графона с разной плотностью присоединенных атомов водорода. $a-$ лента $\mathrm{C}_{100} \mathrm{H}_{12}, b-$ лента $\mathrm{C}_{100} \mathrm{H}_{22}, c$ - лента $\mathrm{C}_{100} \mathrm{H}_{34}$.

связанном с ним атоме углерода - заряд $q_{\mathrm{C}}=-0.22 e$. Энергию кулоновского взаимодействия нужно суммировать по всем атомам углерода и водорода, участвующим в валентных связях $\mathrm{C}-\mathrm{H}$ :

$$
E=\sum_{i<j} k \frac{q_{i} q_{j}}{R_{i j}} .
$$

Невалентные ван-дер-ваальсовы взаимодействия атомов опишем потенциалом Леннарда-Джонса

$$
W_{0}(r)=4 \epsilon_{0}\left[(\sigma / r)^{12}-(\sigma / r)^{6},\right.
$$

где $r$ - расстояние между взаимодействующими атомами, $\epsilon_{0}$ - энергия взаимодействия (равновесная длина связи $\left.r_{0}=2^{1 / 6}(\sigma)\right)$. Для взаимодействующей пары ато- 


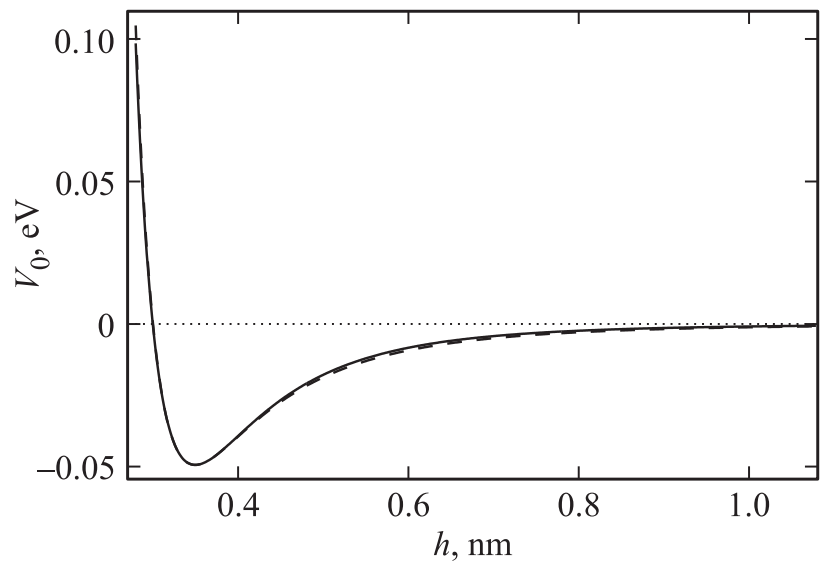

Pис. 3. Зависимость потенциала взаимодействия атома углерода с подложкой от его удаленности от плоской подложки, образованной листом графена. Штриховая кривая - расчетные значения, сплошная - аппроксимация зависимости при помощи аналитического потенциала (7).

мов $\mathrm{C}, \mathrm{C} \epsilon_{0}=0.0028 \mathrm{eV}, \sigma=3.5 \AA$, для пары атомов $\mathrm{C}$, $\mathrm{H} \epsilon_{0}=0.00047 \mathrm{eV}, \sigma=2.9154 \AA$.

Для моделирования наноленты, находящейся на плоской подложке, добавим потенциал, описывающий взаимодействие атома углерода с подложкой,

$$
V_{0}(h)=\epsilon_{h}\left\{\left[\left(h_{0} / h\right)^{9 / 2}-1\right]^{2}-1\right\},
$$

где $h$ - расстояние от атома углерода до плоскости подложки. В качестве подложки будем использовать неподвижный плоский лист графена. Взаимодействие вычислялось как сумма невалентных взаимодействий одного атома углерода со всеми атомами подложки с последующим усреднением положения проекции атома на листе (это позволяет избавиться от дискретности подложки). Вычисление показало, что это взаимодействие наиболее хорошо описывается аналитическим потенциалом (7) со значениями параметров $h_{0}=3.50 \AA$ (равновесное расстояние от атома до плоскости подложки), $\epsilon_{h}=0.0494 \mathrm{eV}$ (энергия взаимодействия атома с подложкой) (рис. 3).

При построении потенциалов взаимодействия использовались силовые поля [16,17], параметры потенциалов слегка менялись для того, чтобы добиться лучшего совпадения основных стационарных состояний малых прямоугольных фрагментов листа графона, полученных при помощи данного набора потенциалов, со стационарными состояниями, полученными из квантово-механических расчетов.

В дальнейшем будем рассматривать прямоугольные фрагменты листа графона с разной плотностью присоединения атомов водорода (рис. 1,2). Краевые атомы будем считать группой атомов $\mathrm{CH}$ с массой $M_{\mathrm{CH}}=13 m_{p}$ $\left(m_{p}\right.$ - масса протона) и рассматривать как одну частицу (это позволит избежать модификации потенциалов взаимодействия для краевых атомов). Внутренние атомы углерода имеют массу $M_{\mathrm{C}}=12 m_{p}$, атомы водорода мaccy $M_{\mathrm{H}}=m_{p}$.
Полная энергия фрагмента листа графона, состоящего из $N$ атомов,

$$
H=\sum_{i=1}^{N} \frac{1}{2} M_{i}\left(\dot{\mathbf{u}}_{i}, \dot{\mathbf{u}}_{i}\right)+E\left(\left\{\mathbf{u}_{i}\right\}_{i=1}^{N}\right),
$$

где $\mathbf{u}_{i}-$ вектор, задающий координаты $i$-го атома, $M_{i}-$ его масса, потенциальная энергия

$$
E=E_{\mathrm{vb}}+E_{\mathrm{va}}+E_{\mathrm{ta}}+E_{\mathrm{vdW}}+E_{C}+E_{\mathrm{sub}},
$$

где первое слагаемое задает энергию деформации всех валентных связей, второе и третье - энергию деформации валентных и торсионных (двугранных) углов, четвертое и пятое - энергию ван-дер-ваальсова и кулоновского взаимодействия атомов листа, последнее слагаемое - энергию взаимодействия атомов с подложкой.

\section{3. Устойчивость односторонней структуры графона к тепловым колебаниям}

Основное стационарное состояние листа графона можно найти численно как решение задачи на минимум энергии

$$
E \rightarrow \min :\left\{\mathbf{u}_{i}\right\}_{i=1}^{N} \cdot
$$

Численное решение этой задачи показало, что все прямоугольные фрагменты листа графона на подложке имеют в основном состоянии плоскую форму (рис. 1), а свободные (не взаимодействующие с подложкой листы) - выпуклую форму (рис. 2).

Для проверки устойчивости структуры листа графона (отсутствия перескоков водорода с одной стороны листа на другую) проводилось молекулярно-динамическое моделирование прямоугольного фрагмента листа размером $5.44 \times 4.218 \mathrm{~nm}$, состоящего из 820 атомов углерода и 333 атомов водорода (рис. 4). В качестве начальной точки было использовано стационарное состояние листа $\left\{\mathbf{u}_{i}^{0}\right\}_{i=1}^{N}$. Для термализации листа был использован термостат Ланжевена, т.е. численно интегрировалась система уравнений движения с трением и случайными силами

$$
\begin{gathered}
M_{i} \ddot{\mathbf{u}}_{i}=-\frac{\partial H}{\partial \mathbf{u}_{i}}-\Gamma M_{i} \dot{\mathbf{u}}_{i}+\Xi_{i}, \\
\dot{\mathbf{u}}_{i}(0)=\mathbf{u}_{i}^{0}, \dot{\mathbf{u}}_{i}(0)=0, \quad i=1, \ldots, N,
\end{gathered}
$$

где $\quad \Gamma=1 / t_{r}-$ коэффициент трения, $\Xi_{i}=$ $=\left(\xi_{i, 1}, \xi_{i, 2}, \xi_{i, 3}\right)$ - вектор случайных сил, нормализованных условиями

$$
\left\langle\xi_{i, k}\left(t_{1}\right) \xi_{j, l}\left(t_{2}\right)\right\rangle=2 M_{i} \Gamma k_{\mathrm{B}} T \delta_{i j} \delta_{k l} \delta\left(t_{1}-t_{2}\right) .
$$

Здесь $k_{\mathrm{B}}-$ постоянная Больцмана, $T-$ температура термостата, время релаксации термостата $t_{r}=0.4 \mathrm{ps}$. Численное интегрирование проводилось с помощью скоростного алгоритма Верле [20]. За время $t=10$ ps лист полностью термализовался, дальше рассматривалась его динамика без взаимодействия с термостатом. 


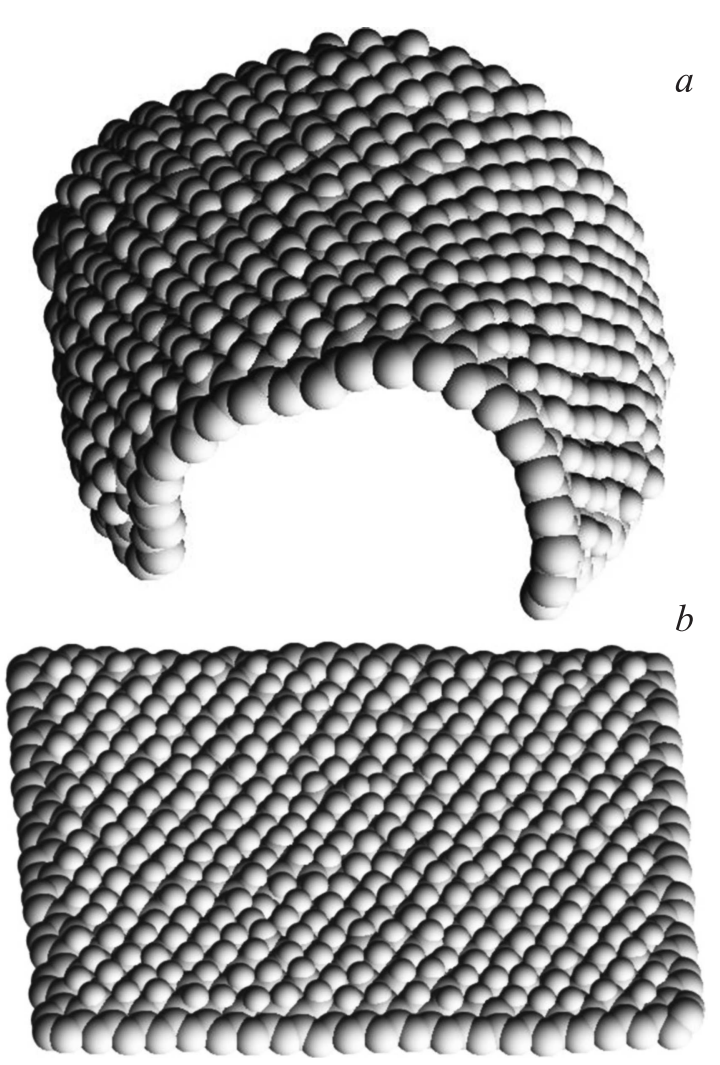

Pис. 4. Типичные конфигурации листа графона $C_{820} \mathrm{H}_{333}$ при температуре $T=900 \mathrm{~K} . a-$ свободный лист, $b-$ взаимодействующий с плоской подложкой лист.

Численное моделирование динамики показало, что при температуре $T=900 \mathrm{~K}$ лист графона не отрывается от подложки за все время моделирования динамики $t=3$ ns. Его форма остается плоской, а атомы водорода всегда остаются только с одной стороны листа (рис. 4 b). Лист, не взаимодействующий с подложкой, сохраняет выпуклую форму, при этом атомы водорода всегда остаются на выпуклой стороне листа (рис. 4, a). Таким образом, при температуре $T<900 \mathrm{~K}$ односторонняя структура листа графона остается устойчивой к тепловым колебаниям. Термически активированные переходы атомов водорода на другую сторону листа становятся возможными, только если не учитывать их ван-дерваальсовы взаимодействия с атомами углерода. Для перехода на другую сторону листа атом водорода должен пройти сквозь шестиугольник жестких валентных связей атомов углерода, чему препятствуют ван-дер-ваальсовы взаимодействия.

\section{4. Рулонные упаковки листа графона}

Самой энергетически выгодной конформацией длинной наноленты графена является ее рулонная упаковка, имеющая в поперечном сечении форму усеченной спирали Архимеда $[21,22]$. Геометрическая форма рулона определяется балансом выигрыша энергии за счет увеличения энергии ван-дер-ваальсовых связей между соприкасающимися слоями рулона и потери энергии на изгиб наноленты. Нанолента графона изначально имеет изгиб (выпуклость в сторону гидрогенизированной поверхности наноленты), что делает ее рулонную упаковку более энергетически выгодной.

Для удобства численного моделирования возьмем узкие „зигзаг“-наноленты графона шириной 7.11 А, представленные на рис. 1 (если наноленту считать квазиодномерной периодической решеткой, то элементарная ячейка этих нанолент состоит из восьми атомов углерода, образующих поперечную цепочку связей со структурой „кресло“). Минимизация потенциальной энергии показывает, что для наноленты, лежащей на подложке, основное состояние имеет плоскую форму. Отметим, что в отличие от случая графена в наноленте графона атомы углерода не лежат в одной плоскости: они образуют складчатую (зигзагообразную в продольном сечении) структуру, идущую вдоль плоскости подложки.

Свободные наноленты графона образуют дугообразные структуры постоянной кривизны с гидрогенизированной внешней поверхностью (кривизна поверхности зависит только от плотности и порядка расположения присоединенных атомов водорода) (рис. 2). Чем длиннее лента, тем больше сближаются концы этих дуг. Существует критическое значение длины наноленты, при котором ван-дер-ваальсово взаимодействие ее концов будет приводить к сворачиванию в рулон.

Характерный вид рулонных упаковок нанолент представлен на рис. 5. Как видно из рисунка, наноленты гра-
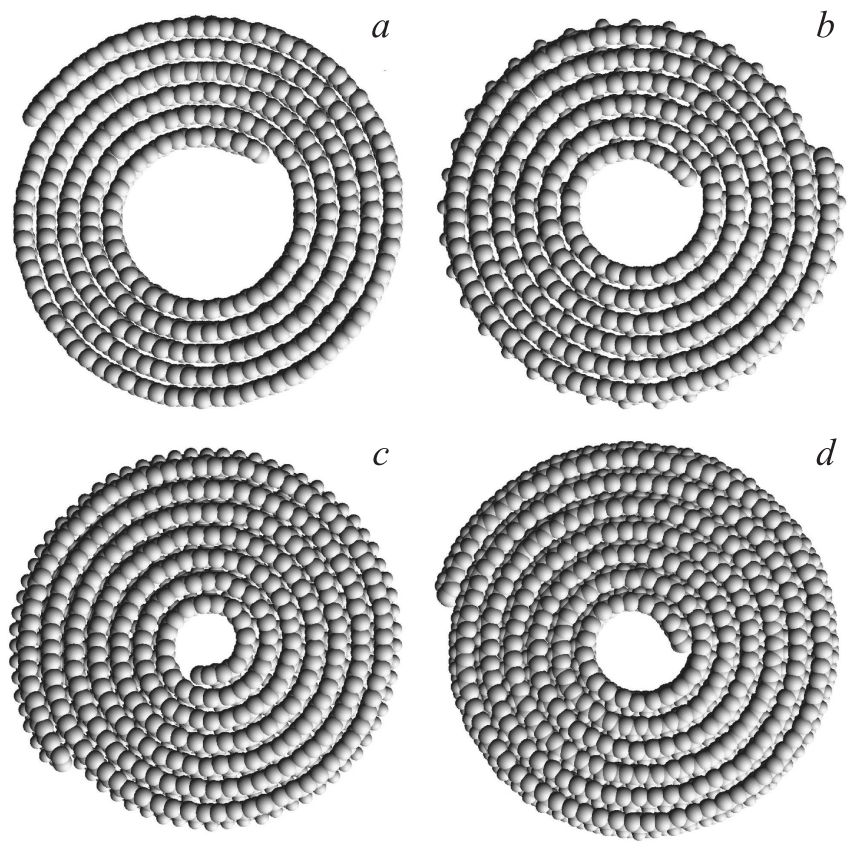

Рис. 5. Рулонные упаковки нанолент длиной $73.6 \mathrm{~nm}$ (вид сбоку). $a-$ нанолента графена $\mathrm{C}_{2404}, b-d-$ наноленты графона $\mathrm{C}_{24} \mathrm{H}_{300}, \mathrm{C}_{2404} \mathrm{H}_{598}$ и $\mathrm{C}_{2404} \mathrm{H}_{898}$ соответственно (их фрагменты представлены на рис. 1). 


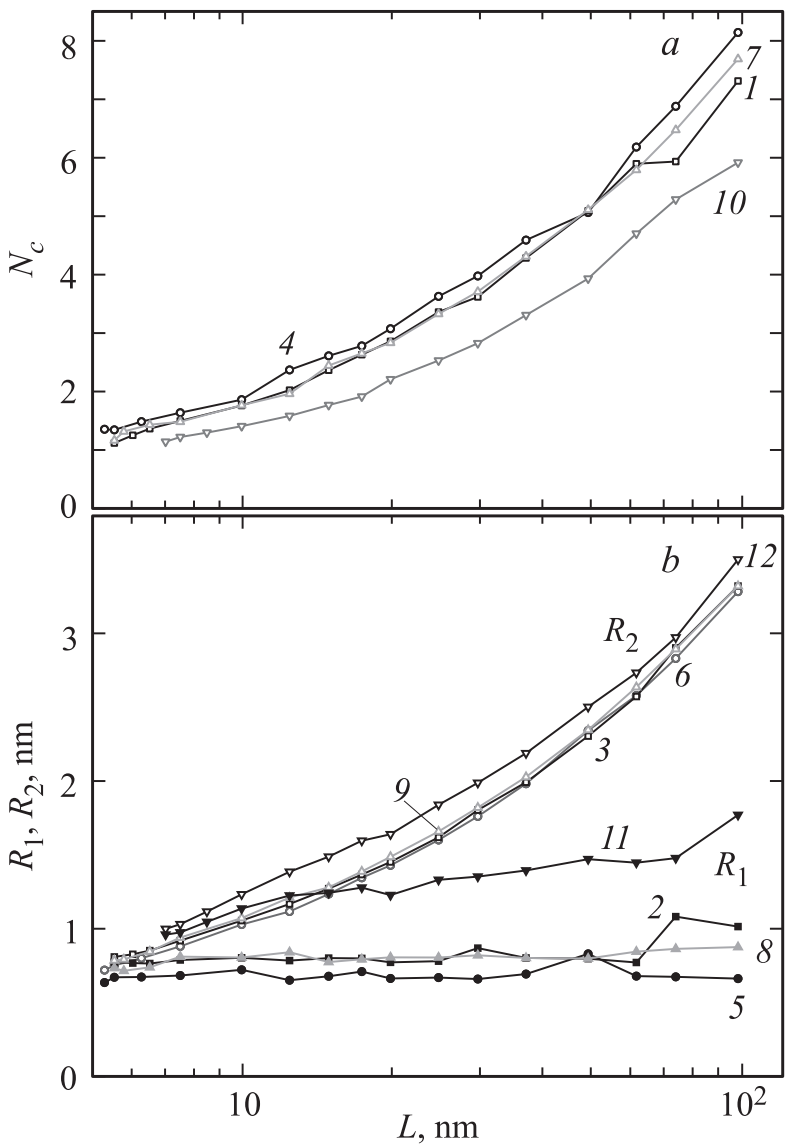

Рис. 6. Зависимости от длины наноленты $L$ числа оборотов рулона $N_{c}(a)$ и внутреннего $R_{1}$ и внешнего $R_{2}$ радиусов рулона $(b)$. Зависимости рассчитаны для нанолент графона, представленных на рис. 1, $a$ (кривые 1-3), рис. 1, $b$ (кривые 4-6), рис. 1, с (кривые 7-9), и для нанолент графена (кривые 10-12).

фона всегда сворачиваются так, чтобы гидрогенизированная поверхность наноленты была внешней стороной рулона. Это является следствием начальной кривизны поверхности графона. Чем сильнее кривизна, тем меньше размер внутренней полости рулона. Самую большую внутреннюю полость имеет рулон наноленты графена, начальная кривизна которого равна нулю. В поперечном сечении рулонные упаковки имеют форму усеченной спирали Архимеда; шаг этой спирали (расстояние между соседними витками рулона) больше для нанолент графона, так как здесь между слоями атомов углерода еще располагается слой атомов водорода.

Геометрию рулона можно охарактеризовать числом витков спирали $N_{c}$ (число оборотов рулона), средним радиусом первого $R_{1}$ (радиус внутренней полости рулона) и последнего витка спирали $R_{2}$ (радиус рулона по внешней поверхности) [22]. При определении $N_{c}, R_{1}, R_{2}$ за центр рулона берется его центр тяжести.

Зависимости числа витков $N_{c}$ и радиусов рулона $R_{1}$, $R_{2}$ от длины наноленты $L$ представлены на рис. 6 . Как видно из рисунка, число витков рулона монотонно рас- тет с увеличением длины наноленты. Также монотонно растет и внешний радиус рулона, величина которого слабо зависит от степени насыщенности внешней поверхности наноленты атомами водорода. Рулоны графона также характеризуются независимостью радиуса внутренней полости от длины наноленты (для графена радиус внутренней полости рулона монотонно растет с увеличением длины наноленты). Рис. 5 и 6 показывают, что наноленты графона скручиваются в более плотные рулоны, чем наноленты графена. Это происходит изза неэквивалентности сторон наноленты. Поэтому для графона рулон является „естественным“ основным состоянием.

\section{5. Самосборка нанолент графона в рулоны}

Для моделирования образования рулонных структур рассмотрим наноленты размером $2.53 \times 0.711 \mathrm{~nm}$. Нанолента графена такого размера состоит из 804 атомов углерода $\left(\mathrm{C}_{804}\right)$, наноленты графона имеют дополнительно 100 атомов водорода $\left(\mathrm{C}_{804} \mathrm{H}_{100}\right), 198$ атомов $\left(\mathrm{C}_{804} \mathrm{H}_{198}\right)$ и 298 атомов $\left(\mathrm{C}_{804} \mathrm{H}_{298}\right)$. Короткие наноленты графона $\left(\mathrm{C}_{100} \mathrm{H}_{12}, \mathrm{C}_{100} \mathrm{H}_{22}, \mathrm{C}_{100} \mathrm{H}_{34}\right)$ представлены на рис. 1.

Будем считать, что вначале нанолента лежит на плоской подложке. При помощи уравнения Ланжевена (10) термализуем ее до температуры $T=300 \mathrm{~K}(900 \mathrm{~K})$. После этого рассмотрим динамику наноленты в отсутствие ее взаимодействия с подложкой и термостатом. Для анализа конформации наноленты удобно следить за изменением числа витков $N_{c}$ (для плоской наноленты $\left.N_{c}=0.5\right)$.

Численное моделирование динамики показывает, что наноленты графона сворачиваются в рулон за $100 \mathrm{ps}$, а нанолента графена за все время моделирования $(2 \mathrm{~ns})$ не образует рулона (рис. 7). После удаления подложки нанолента начинает принимать форму выпуклой в сторону гидрогенизированной поверхности арки, изгиб которой монотонно растет, а края сближаются. При сближении концов возникает их ван-дер-ваальсово взаимодействие, в результате которого нанолента быстро сворачивается в рулон: в интервале времени $0<t<100$ ps происходит монотонный рост числа витков. Число витков достигает постоянного значения $(\sim 3)$, после чего начинает совершать около этого значения низкочастотные периодические колебания, которые соответствуют самой низкочастотной моде рулона, т.е. его периодическому частичному скручиванию-раскручиванию.

Сворачивание рулона происходит так, что гидрогенизированная поверхность наноленты всегда остается внешней. При образовании рулона выделяется энергия, приводящая к повышению температуры ленты на $\sim 100 \mathrm{~K}$. Из рис. 7 хорошо видно, что тепловые колебания не препятствуют образованию рулона, а сам рулон устойчив к ним даже при температуре $T=1000 \mathrm{~K}$. 

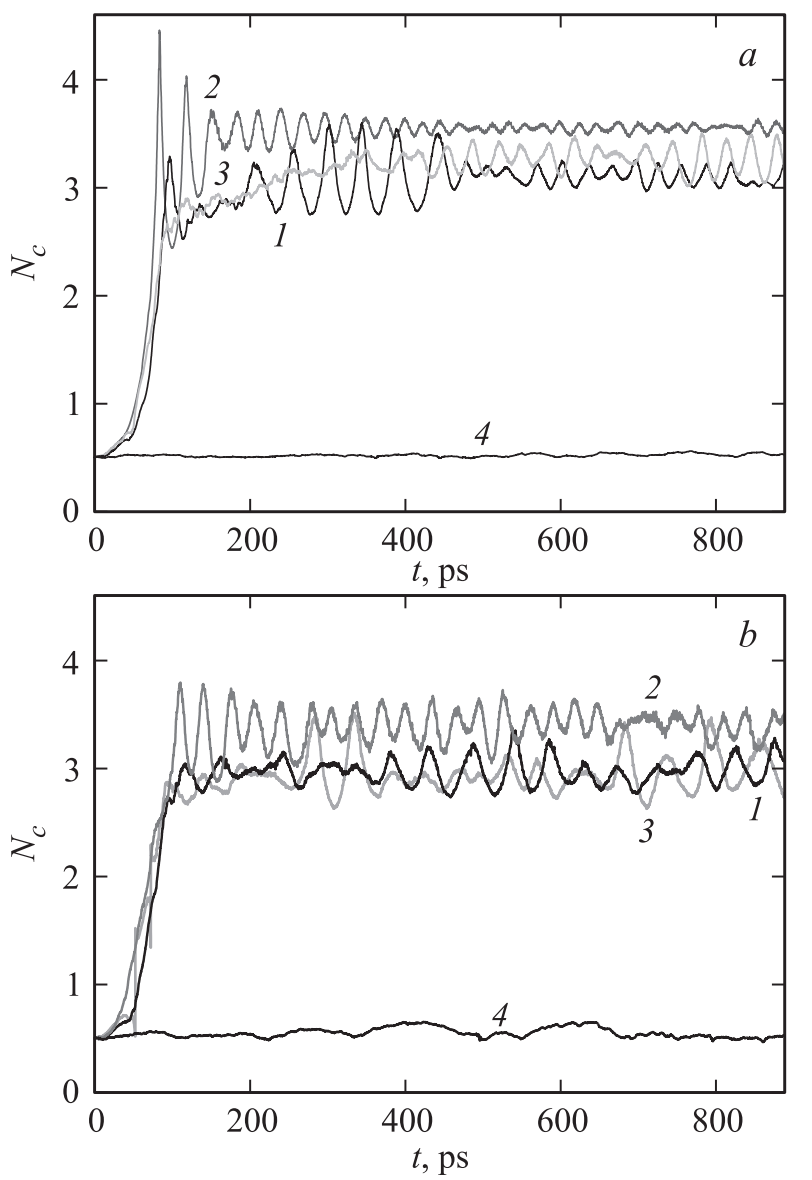

Рис. 7. Зависимости от времени $t$ числа витков $N_{c}$ нанолент $\mathrm{C}_{804} \mathrm{H}_{100}(1), \mathrm{C}_{804} \mathrm{H}_{198}$ (2), $\mathrm{C}_{804} \mathrm{H}_{298}$ (3), $\mathrm{C}_{804}$ (4) при температуре $T=300(a)$ и $900 \mathrm{~K}(b)$.

В отличие от случая графона свободные наноленты графена имеют плоскую форму, их изгиб может происходить только вследствие тепловых колебаний. Поэтому здесь сворачивание в рулон требует, как правило, специальных условий.

Самосборка нанолент графона в рулоны объясняет образование рулонных структур при использовании гидротермального метода получения углеродных нанотрубок, при котором разогретый до температуры $800-900^{\circ} \mathrm{C}$ поликристаллический графит опускают в сосуд с дистиллированной водой комнатной температуры $[14,15]$. Здесь должно происходить не образование многослойных нанотрубок графена, а образование внешне подобных им рулонных упаковок односторонне гидрированных нанолент по следующему сценарию: гидрирование внешнего плоского слоя кристалла графита, отделение его от подложки и дальнейшее сворачивание в рулон.

\section{6. Заключение}

Проведенное с использованием молекулярно-механической модели численное моделирование динамики на- нолент графона показало, что свободные наноленты большой длины всегда собираются в рулонные упаковки, внешние стороны которых образуют поверхности с присоединенными атомами водорода. Наноленты и их рулонные упаковки устойчивы к тепловым колебаниям при температуре $T<900 \mathrm{~K}$. Термически активированных переходов атомов водорода с одной стороны наноленты на другую не происходит, атомы водорода всегда остаются на одной стороне наноленты.

\section{Список литературы}

[1] K.S. Novoselov, A.K. Geim, S.V. Morozov, D. Jiang, Y. Zhang, S.V. Dubonos, I.V. Grigorieva, A.A. Firsov. Science 306, 666 (2004).

[2] A.K. Geim, K.S. Novoselov. Nature Mater. 6, 183 (2007).

[3] C. Soldano, A. Mahmood, E. Dujardin. Carbon 48, 2127 (2010).

[4] А.Л. Ивановский. Успехи химии 81, 571 (2012).

[5] J.O. Sofo, A.S. Chaudhari, G.D. Barber. Phys. Rev. B 75, 153401 (2007).

6] D.C. Elias, R.R. Nair, T.M.G. Mohiuddin, S.V. Morozov, P. Blake, M.P. Halsall, A.C. Ferrari, D.W. Boukhalov, M.I. Katsnelson, A.K. Geim, K.S. Novoselov. Science 323, 610 (2009).

[7] J. Zhou, Q. Wang, Q. Sun, X.C. Chen, Y. Kawazoe, P. Jena. Nano Lett. 9, 3867 (2009).

[8] R. Balog, B. Jorgensen, L. Nilsson, M. Andersen, E. Rienks, M. Bianchi, M. Fanetti, E. Lagsgaard, A. Baraldi, S. Lizzit, Z. Sljivancanin, F. Besenbacher, B. Hammer, T.G. Pedersen, P. Hofmann, L. Hornekar. Nature Mater. 9, 315 (2010).

[9] D.W. Boukhvalov. Physica E 43, 199 (2010).

[10] R. Ruoff. Nature Nanotechnol. 3, 10 (2008).

[11] J.S. Burgess, B.R. Matis, J.T. Robinson, F.A. Bulat, F.K. Perkins, B.H. Houston, J.W. Baldwin. Carbon 49, 4420 (2011).

[12] C.D. Reddy, Y.-W. Zhang. Carbon 69, 86 (2014).

[13] А.И. Подливаев, Л.А. Опенов. ФТП 45, 988 (2011).

[14] Z.H. Kang, E.B. Wang, L. Gao, S.Y. Lian, M. Jiang, C.W. Hu, L.J. Xu. J. Am. Chem. Soc. 125, 13652 (2003).

[15] Е.А. Беленков, Ф.К. Шабиев. Письма о материалах 5, 459 (2015).

[16] A.V. Savin, Yu.S. Kivshar, B. Hu. Phys. Rev. B 82, 195422 (2010).

[17] W.D. Cornell, P. Cieplak, C.I. Bayly, I.R. Gould, K.M. Merz, D.M. Ferguson, D.C. Spellmeyer, T. Fox, J.W. Caldwell, P.A. Kollman. J. Am. Chem. Soc. 117, 5179 (1995).

[18] G.M. Chechin, S.V. Dmitriev, I.P. Lobzenko, D.S. Ryabov. Phys. Rev. B 90, 045432 (2014).

[19] S. Casolo, O.M. Lovvik, R. Martinazzo, G.F. Tantardini. J. Chem. Phys. 130, 054704 (2009).

[20] L. Verlet. Phys. Rev. 159, 98 (1967); 165, 201 (1968).

[21] А.В. Савин, Е.А. Корзникова, С.В. Дмитриев. ФТТ 57, 2278 (2015).

[22] A.V. Savin, E.A. Korznikova, S.V. Dmitriev. Phys. Rev. B 92, 035412 (2015). 